\title{
Assessment of the effect of left atrial cryoablation enhanced by ganglionated plexi ablation in the treatment of atrial fibrillation in patients undergoing open heart surgery
}

\author{
Jiři Bárta* (iD and Radim Brát
}

\begin{abstract}
Background: The aim of our study was to investigate, whether enhancement of left atrial cryoablation by ablation of the autonomic nervous system of left atrium leads to influencing the outcomes of surgical treatment of atrial fibrillation in patients with structural heart disease undergoing open-heart surgery.

Methods: The observed patient file consisted of 100 patients, who have undergone a combined open-heart surgery at our department between July 2012 and December 2014. The patients were indicated for the surgical procedure due to structural heart disease, and suffered from paroxysmal, persistent, or long-standing persistent atrial fibrillation. In all cases, left atrial cryoablation was performed in the extent of isolation of pulmonary veins, box lesion, connecting lesion with mitral annulus, amputation of the left atrial appendage and connecting lesion of the appendage base with left pulmonary veins. Furthermore, 35 of the patients underwent mapping and radiofrequency ablation of ganglionated plexi, together with discision and ablation of the ligament of Marshall (Group GP). A control group was consisted of 65 patients without ganglionated plexi intervention (Group LA). The main primary outcome was establishment and duration of sinus rhythm in the course of one-year follow-up.

Results: Evaluation of the number of patients with a normal sinus rhythm in per cent has shown comparable values in both groups (Group GP - 93.75\%, Group LA - 86.67\%, $p=0.485$ ); comparable results were also observed in patients with normal sinus rhythm without anti-arrhythmic treatment in the 12th month (Group GP - 50\%, Group LA - 47\%, $p=0.306)$. We have not observed any relation between the recurrence of atrial fibrillation and the presence of a mitral valve surgery, or between the presence of a mitral and tricuspid valves surgery and between the left atrial diameter $>50 \mathrm{~mm}$.
\end{abstract}

Conclusions: Enhancement of left atrial cryoablation by gangionated plexi ablation did not influence the outcomes of surgical ablation due to atrial fibrillation in our population in the course of 12-month follow-up.

Trial registration: The study was approved retrospectively by the Ethics Committee of the University Hospital Ostrava (reference number 867/2016).

Keywords: Atrial fibrillation, Left atrial cryoablation, Ganglionated plexi, Open-heart surgery

* Correspondence: jiribarta.klimkovice@seznam.cz

Cardiac Surgery, University Hospital Ostrava, 17.listopadu 1790, 70852

Ostrava-Poruba, Czech Republic 


\section{Background}

The growing incidence of atrial fibrillation (AF) in the population [1] and its clinical [1] and economical [2] importance supports the progressive growth of research of pathophysiology of atrial fibrillation and factors influencing the initiation and maintenance of this most frequently observed heart arrhythmia in the last decades, which is reflected also in the frequency of updates of Guidelines for treatment of AF issued by various cardiology and heart surgery expert societies.

One of the main factors playing an important role in the initiation and duration of atrial fibrillation is the Autonomic Nervous System (ANS) [3-5]. ANS may be divided into two main components - extrinsic and intrinsic [6]. Extrinsic ANS has a sympathetic and parasympathetic branch. Sympathetic fibres originate from the ganglia along cervical and thoracic spine, and end at the heart surface. Parasympathetic fibres originate in nucleus ambigus in medulla oblongata, and continue as a part of nervus vagus; most of them terminate in the adipose tissue (fat pad) between the superior vena cava and the aorta [7]. Intrinsic ANS is formed with a number of heart ganglia, containing approximately 200-1000 neurons, and synapses of sympathetic and parasympathetic fibres $[8,9]$. Most of the ganglia are organized in ganglionated plexi (GP), embedded in epicardial fat pads on the surface of atria and ventricles. They participate upon the interconnection and modulation of interactions between extrinsic and intrinsic ANS [10], and, apart from others, influence the function of the sinoatrial and atrioventricular node $[11,12]$.

Already in 1978, Coumel et al. [13] in their work pointed out the fact that under certain conditions, the activity of intrinsic ANS may cause paroxysm of atrial arrhythmia. Other works looking into with a more detailed study of intrinsic ANS show the possibility of evocation of rapid trigger activity with stimulation of intrinsic ANS, with electric impulses [14], as well as administration of autonomous neurotransmitters [15-17]. This trigger activity is most frequently observed in myocardial sleeves of the pulmonary veins [18]. The mechanism behind the initiation of trigger activity is a vegetative influencing of the intracellular level of calcium ions, and the length of duration of the action potential by causing early after depolarisations [19]. Apart from this, further changes of autonomous regulation (autonomous remodelling) may, in interaction with other AF mechanisms (with structural remodelling) lead to a formation of a substrate, which is so important for maintenance of AF [20]. Clinical trials dealing with catheterization therapy of AF present a significant improvement of the outcomes in cases of enhancement of the catheterization ablation by GP ablation [21-23]. In accordance with the outcomes of these studies, also other outcomes of surgical treatment of lone AF via minimally invasive surgical approach are presented [24-26]. The aim of our study was to investigate, whether enhancement of left atrial cryoablation by ablation of the autonomic nervous system of left atrium leads to influencing the outcomes of surgical treatment of atrial fibrillation in patients with structural heart disease undergoing openheart surgery.

\section{Methods}

\section{Patient selection}

The our patient population consisted of 1 hundred subjects, who underwent an open-heart surgery between July 2012 and December 2014. All procedures were performed at Department of Cardiac Surgery, University Hospital Ostrava, Czech Republic. Written informed consent was obtained from all patients prior surgery. Data were obtained from the National Registry of Cardiac Surgery, Czech Republic and were analysed retrospectively.

The patients suffered from structural heart disease, which was the basic indication for the heart surgery procedure, together with one type of atrial fibrillation (paroxysmal, persistent, or long-standing persistent), due to which left atrial cryoablation was performed as a part of the surgical procedure. Extent of left atrial ablation procedure is described below. Thirty-five patients (35\%) from these population underwent concomitant mapping and radiofrequency ablation of ganglionated plexi (Group GP) whereas 65 patients (65\%) had no ganglionated plexi intervention (Group LA). Both groups were comparable and no significant differences were observed in the monitored preoperative comorbidities, apart from the incidence of Stroke/Transitory Ischemic Attack (TIA) in the history of the patients. Preoperative data are presented in Table 1 . The representation of individual types of atrial fibrillation in both groups was also comparable, and is presented in Table 2.

\section{Surgical technique}

All patients underwent an open-heart surgery from median sternotomy, with the use of extracorporeal circulation, with bicaval cannulation and venting of arteria pulmonalis. In patients in the Group GP, mapping of GP around the orifice of pulmonary veins (PVs) (Fig. 1 and Fig. 2) was performed in the first stage, together with their radiofrequency (RF) ablation. In the area of rightside PVs, the procedure was performed prior to initiation of extracorporeal circulation (ECC). In case of the left-side PVs; the procedure was performed after initiation of ECC. Part of this procedure was also a discision and ablation of the ligament of Marshall.

GP mapping was performed with "Isolator Multifunctional Pen" (AtriCure, West Chester, Ohio, USA), using high-frequency stimulation (1000 beats $\mathrm{min}^{-1}$, potential 
Table 1 Preoperative variables. Data are presented as mean \pm standard deviation or as number of patients with percentages. TIA, transitory ischemic attack; NYHA, New York Heart Assotiation; CHADS-VASC, congestive heart failure, hypertenstion, age, diabetes, prior stroke, vascular disease history, age, sex; LV EF, left ventricular ejection fraction; LVED, left ventricular end-diastolic diameter

\begin{tabular}{|c|c|c|c|}
\hline & $\begin{array}{l}\text { Group GP } \\
n=35\end{array}$ & $\begin{array}{l}\text { Group LA } \\
n=65\end{array}$ & $p$ value \\
\hline Age & $69 \pm 6.4$ & $69 \pm 7.4$ & 0.617 \\
\hline $\operatorname{Sex}(M / F)$ & 18/17 (51/49) & $31 / 34(48 / 52)$ & 0.721 \\
\hline Body mass index & $31 \pm 4.9$ & $30 \pm 4.9$ & 0.099 \\
\hline Hypertension & $32(91)$ & $53(81)$ & 0.186 \\
\hline Diabetes mellitus & $9(26)$ & $12(18)$ & 0.396 \\
\hline Creatinine & $103 \pm 45.4$ & $102 \pm 27.2$ & 0.298 \\
\hline Stroke/TIA & $2(6)$ & $14(22)$ & 0.040 \\
\hline Redo cardiac surgery & 0 & $1(2)$ & \\
\hline NYHA & 2 & 2 & 0.999 \\
\hline Euroscore II & $4 \pm 2.4$ & $4 \pm 4.7$ & 0.301 \\
\hline CHA2DS2-VASc score & $3.8 \pm 1.4$ & $3.6 \pm 1.5$ & 0.387 \\
\hline \multicolumn{4}{|l|}{ Structural cardiac disease } \\
\hline Mitral valve disease & $25(71)$ & $49(75)$ & 0.667 \\
\hline $\begin{array}{l}\text { Tricuspidal valve } \\
\text { disease }\end{array}$ & $17(49)$ & $34(52)$ & 0.721 \\
\hline Aortic valvae disease & $6(17)$ & $18(28)$ & 0.239 \\
\hline Coronary artery disease & $21(60)$ & $32(49)$ & 0.303 \\
\hline Other & $4(11)$ & $15(23)$ & 0.157 \\
\hline LV EF (\%) & $45 \pm 10.2$ & $50 \pm 9.8$ & 0.057 \\
\hline $\mathrm{EF} L K>50 \%$ & $15(43)$ & $42(65)$ & \\
\hline EF LK 30-50\% & $17(49)$ & $20(31)$ & \\
\hline EF LK $<30 \%$ & $3(8)$ & $3(4)$ & 0.109 \\
\hline Left atrium diameter (mm) & $45 \pm 4.8$ & $47 \pm 5.5$ & 0.544 \\
\hline LVED diameter (mm) & $54 \pm 6.7$ & $51 \pm 5.8$ & 0.086 \\
\hline
\end{tabular}

$18 \mathrm{~V}$, pulse width $1.5 \mathrm{~ms}$ ), and PACE $203 \mathrm{H}$ external stimulator (OSCOR Inc., Palm Harbor, USA). The indication for GP ablation was a doubling in the R-R interval in the sinus rhythm, or ventricular rate slowing of more that 50\% [27] associated with a decrease of blood pressure $>20 \mathrm{mmHg}$ in patients with AF [28]. In case of a positive response, radiofrequency ablation of the ganglia was performed following switching of the pen at the

Table 2 Type of atrial fibrilation. Data are presented as number of patient with percentages

\begin{tabular}{llll}
\hline Type of atrial fibrilation & $\begin{array}{l}\text { Group GP } \\
n=35\end{array}$ & $\begin{array}{l}\text { Group LA } \\
n=65\end{array}$ & $p$ value \\
\hline Paroxysmal & $14(40)$ & $28(43)$ & \\
Persistent & $15(43)$ & $24(37)$ & \\
Longstanding persistent & $6(17)$ & $13(20)$ & 0.838 \\
\hline
\end{tabular}

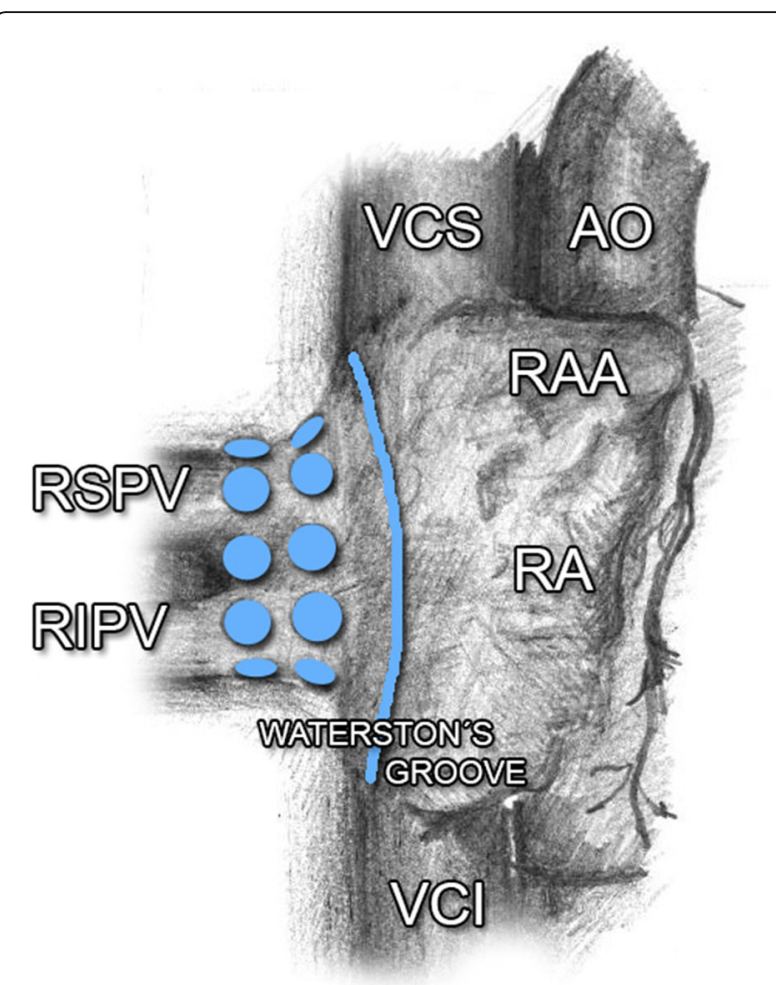

Fig. 1 Ganglionated plexi around the orifice of right PVs. AO, aorta; PVs, pulmonary veins; RA, right atrium; RAA, right atrial appendage; RIPV, right inferior pulmonary vein; RSPV, right superior pulmonary vein; VCS, vena cava superior; $\mathrm{VCl}$, vena cava inferior

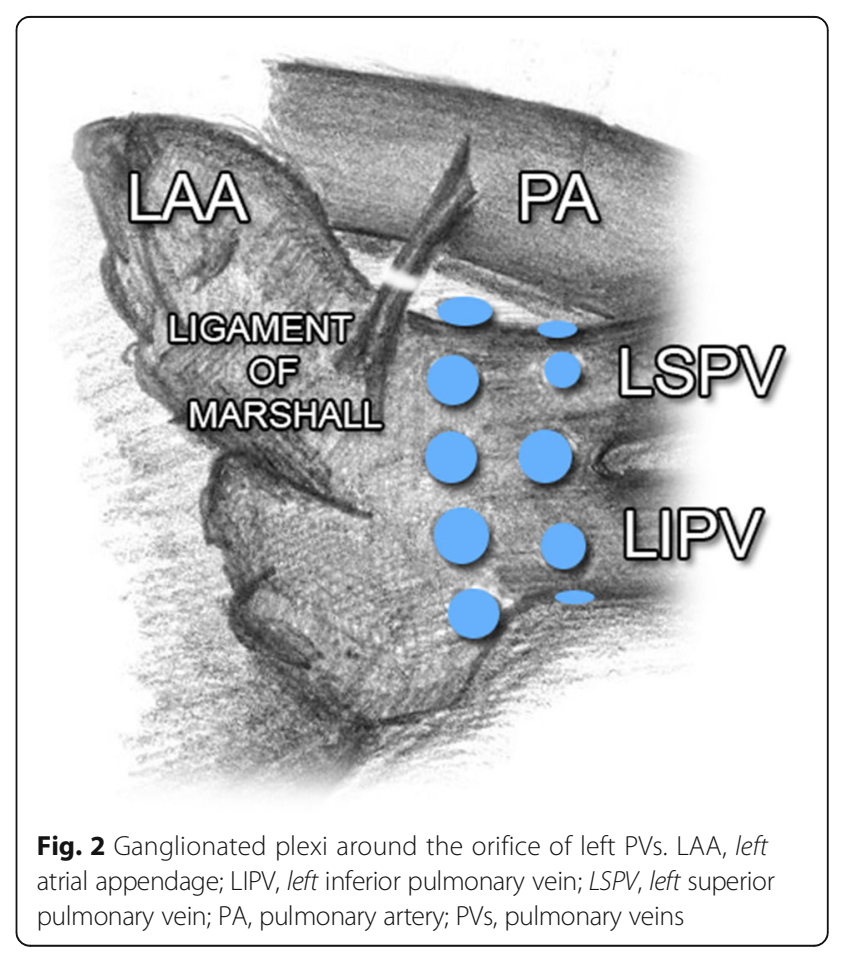


console. This procedure was repeated until the activity of the ganglia has disappeared. The following stage of the surgical procedure was identical for both groups of patients. After aortic cross-clamping and administration of cardioplegia, heart surgery procedure was performed, a part of which was the left atrial cryoablation in the extent of the right-side and left-side PVs isolation, box lesion (connecting right and left PVs lesions), lesion of the left atrium isthmus (connecting lesion with mitral annulus), resection of the left atrial appendage, and connecting lesion of the appendage base with left superior PV (Fig. 3). The procedure was performed with the Cardioblate Cryoflex probe (The Cardioblate CryoFlex Argon-powered Cryoablation System, Medtronic USA, Inc.). Lesions were created by temperature from -120 to $-160{ }^{\circ} \mathrm{C}$, administered for the period of $60 \mathrm{~s}[29,30]$. When the left atrium was opened, lesions were done endocavitally, and epicardially in other cases. The performed surgical procedures and duration of extracorporeal circulation are presented in Table 3.

\section{Statistical analysis}

In order to describe the patient file, basic descriptive statistics methods were used (median, arithmetical mean, standard deviation, frequency tables).

For quantitative variables, Shapiro-Wilk test of normality was used. Based upon data distribution, twochoice t-test, or non-parametric two-choice Wilcoxon test was used to compare the patient files. In order to test the difference of qualitative variables, chi-quadrate test was used, or Fisher's exact test (in cases when it was not possible to use the chi-quadrate test).

In order to assess the parameters prior to the procedure and at 1 year after the procedure, paired t-test was

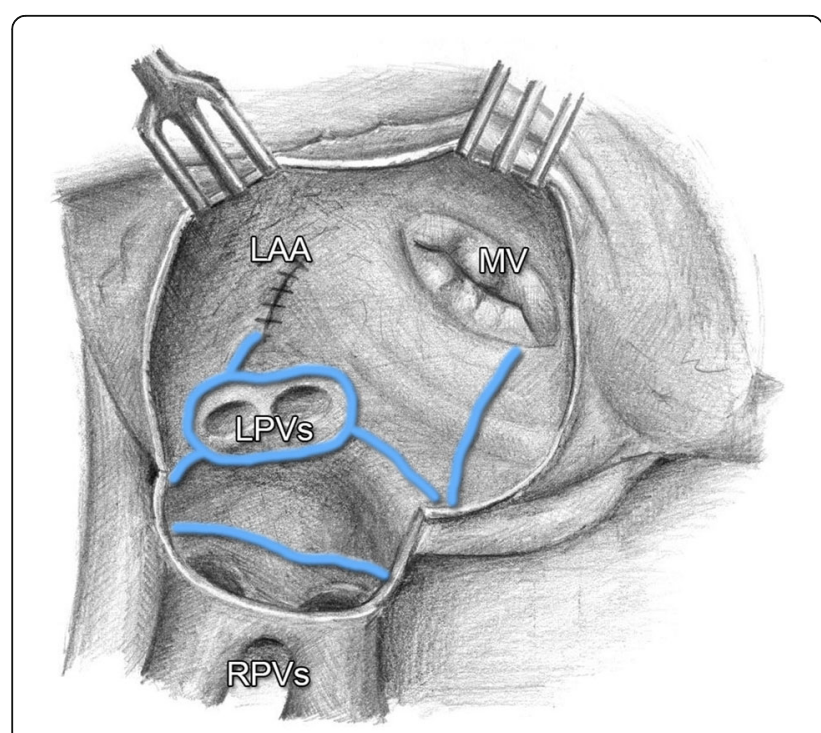

Fig. 3 Left atrial cryoablation lesion set. LAA, left atrial appendage; MV, mitral valve; LPVs, left pulmonary veins; RPVs, right pulmonary veins
Table 3 Main surgery procedures. Data are presented as mean \pm standard deviation or as number of patients with percentages. MV, mitral valve; $\mathrm{TV}$, tricuspidal valve; $\mathrm{AV}$, atrial valve; $C A B G$, coronary artery bypass graft; ECC, extracorporeal circulation

\begin{tabular}{lccc}
\hline $\begin{array}{l}\text { Group GP } \\
n=35\end{array}$ & $\begin{array}{l}\text { Group LA } \\
n=65\end{array}$ & p value \\
\hline MV repair & $19(54)$ & $40(62)$ & \\
MV replacement & & & \\
$\quad$ mechanical prosthesis & $2(6)$ & $2(3)$ & \\
$\quad$ biological prosthesis & $4(11)$ & $7(11)$ & 0.863 \\
TV repair & $17(49)$ & $34(52)$ & 0.721 \\
AV replacement & & & \\
$\quad$ mechanical prosthesis & $1(3)$ & $2(3)$ & \\
$\quad$ biological prosthesis & $5(14)$ & $15(23)$ & 0.570 \\
CABG & $15(43)$ & $26(40)$ & 0.782 \\
Other & $4(11)$ & $15(23)$ & 0.157 \\
Cross-clamp time & $87 \pm 26.4$ & $97 \pm 27.8$ & \\
ECC time & $140 \pm 41.4$ & $135 \pm 36.8$ & 0.429 \\
\hline
\end{tabular}

used for quantitative variables, and symmetry test was used for qualitative variables. In order to obtain graphical representation, bar charts were used. The statistical tests were evaluated at the level of significance of $5 \%$. The Stata programme, version 13 was used in order to process the statistical results.

The statistical analysis was performed at the Centre of Epidemiology Research, Faculty of Medicine, University of Ostrava.

\section{Postoperative management}

The patients using anti-arrhythmic medication prior to the surgery procedure continued in taking the medication also in the post-operative period, unless the medication was contraindicated for any reason (e.g. serious heart rhythm disorders). In the therapy of postoperative AF, anti-arrhythmic medication Class Ic, II, III, IV and V was used (Vaughan Williams classification). The Class II (ß-blockers) was excluded from the assessment of frequency of the anti-arrhythmic medication in time of follow up. The anti-arrhythmic medication of the first choice was Amiodarone. Its saturation was initiated with intravenous infusion, with subsequent per oral medication use. Unless pharmacological version was performed, electrical cardioversion was performed in order to achieve the effective level of Amiodarone $(>6 \mathrm{~g})$. In case of patients in whom administration of Amiodarone was contraindicated, other suitable anti-arrhythmic medication or combination of such was used. Anticoagulation medication (Warfarin) was administered in all patients after heart valve surgery. In patients using anticoagulation medication prior to the surgery for $\mathrm{AF}$, 
administration of the medication continued also after the procedure. In patients with postoperative arrhythmia, Warfarin was administered in cases, when the arrhythmia lasted for the period exceeding $48 \mathrm{~h}$. The dose of Warfarin was chosen according to the assessment of prothrombin time and the range of therapeutic level according to the International Normalized Ratio (INR); the length of duration was chosen according to the type of indication of the respective anticoagulation medication. The duration of therapy administered due to AF was 3 months. Following medication management was performed depending on the heart rhythm.

\section{Follow up}

Assessment of the heart rhythm in patients was performed at 7 day, at 3 and 12 months after the surgical procedure. Heart rhythm was monitored continuously in all patients after the surgery. On the seventh postoperative day, evaluation of the heart rhythm was performed, using the record for the last $24 \mathrm{~h}$. In the third and twelfth postoperative month, the patients were examined by a cardiologist in at our outpatient clinic. The assessment included collection of history, performance of physical examinations, 12-lead electrocardiography (ECG) and echocardiography (ECHO) examination. The assessment of heart rhythm was based on 24-h Holter monitoring, which was performed at our outpatient clinic, or by reffering cardiologists. Recurrent AF was defined as arrhythmia (AF, flutter, atrial tachycardia) lasting at least 30s. Patient medication was adjusted according to the findings of cardiology examination; also the possibility of performing electric cardioversion was considered, together with the need of implantation of permanent cardiostimulation.

\section{Results}

\section{Postoperative results}

No complications related to the ablation procedure were observed peroperatively or postoperatively. Overall 30day mortality was $4 \%$ : one patient died in the Group GP (2.9\%), three patients died in the Group LA (4.6\%). The average EUROscore of the deceased patients was 4.01\%.

The average length of hospitalization in our patient file was 15.7 days (Group GP 15 days, Group LA 16.3 days).

Due to serious postoperative complications, revisions were performed due to bleeding $(n=4)$, renal insufficiency requiring haemodialysis $(n=5)$, stroke/TIA $(n=1)$, sternal osteomyelitis $(n=1)$, Multiple Organ Dysfunction Syndrome (MODS) $(n=3)$, heart failure $(n=3)$, Acute Myocardial Infarction (AMI) $(n=1)$, respiratory insufficiency requiring re-intubation $(n=6)$, and bronchopneumonia $(n=8)$. These complications were observed in the total of 18 patients (Group GP 7 (20\%), Group LA $11(17 \%), p=0.702)$. A higher accumulation ( 2 to 5 ) was noted in eight patients. In most cases, these patients died within 30 days.

\section{Follow up results}

In the course of the 12-month follow up, one patient died in the Group GP, and one patient interrupted his contact with our outpatient clinic, two patients died in the Group LA. The final statistical analysis contains only the data from the patients, who remained in the study for whole follow-up period (Group GP $n=32$, Group LA $n=60$ ).

The number of patients with NSR and AF in individual phases of follow-up, either in the subgroups - GP and LA, or in subgroups according to the type of fibrillation, is presented in Fig. 4. and Fig. 5.

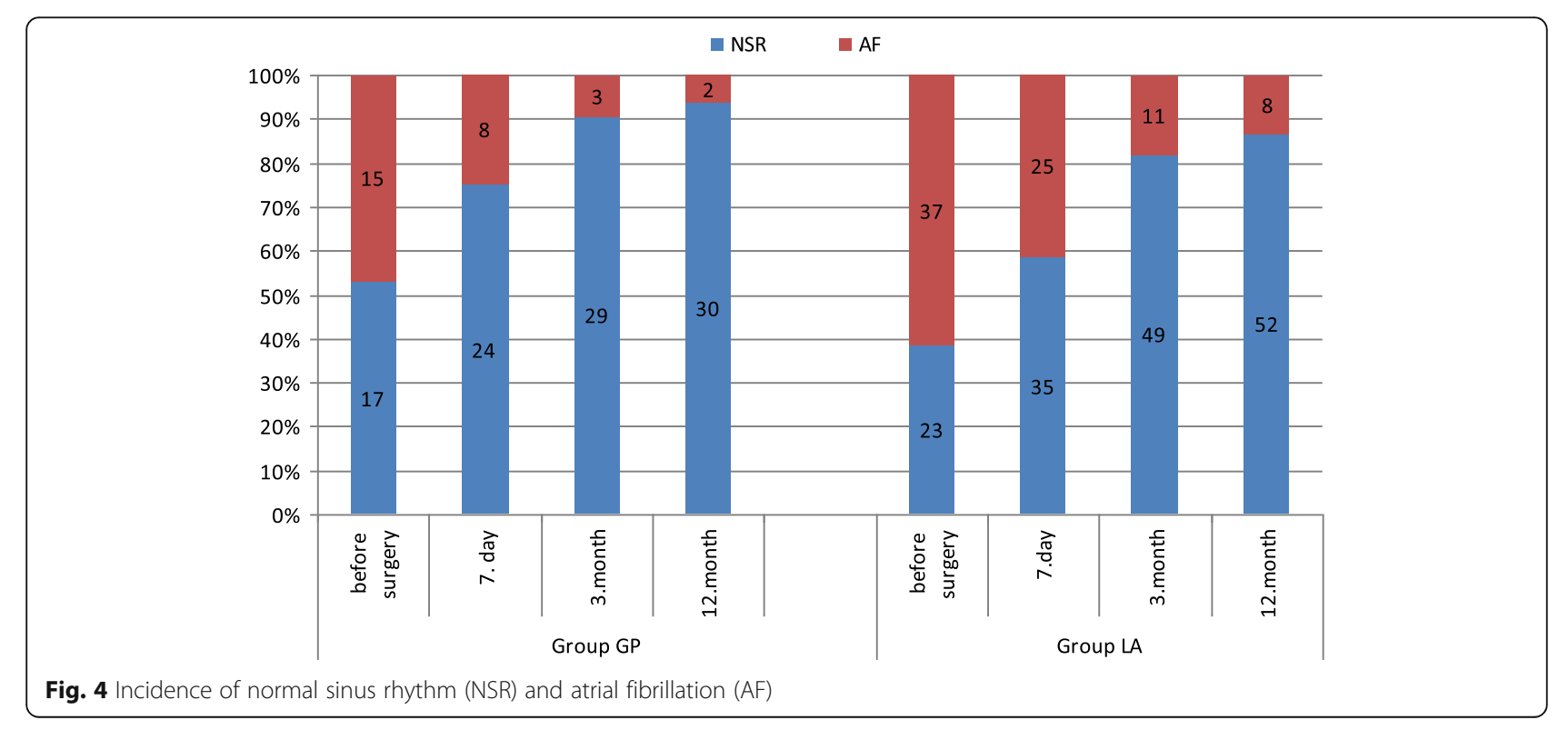




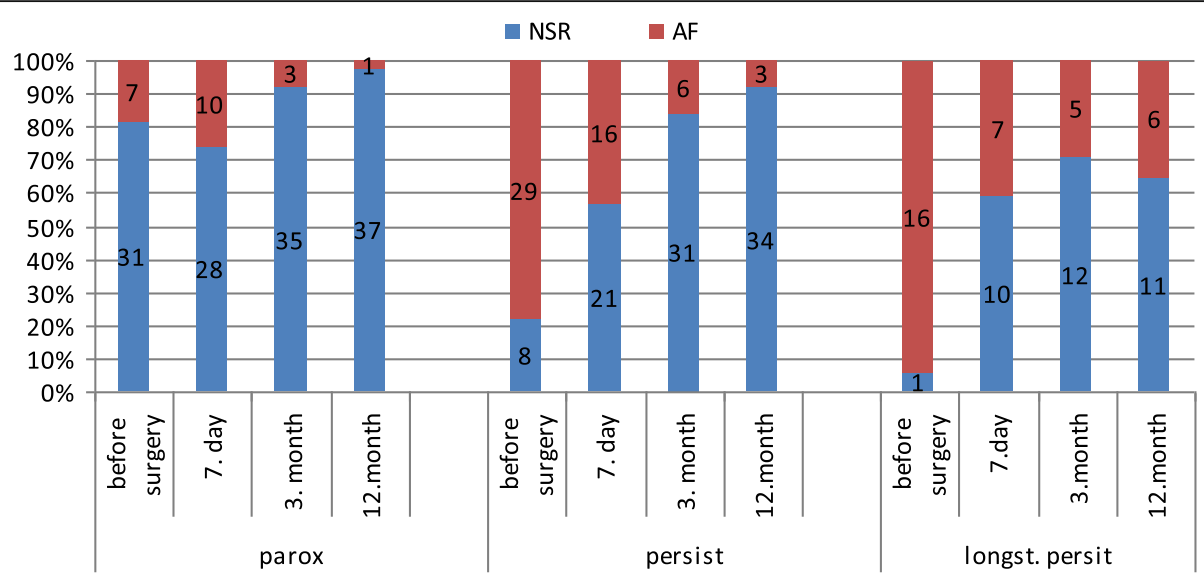

Fig. 5 Incidence of normal sinus rhythm (NSR) and atrial fibrillation (AF) according to type of AF

The normal sinus rhythm (NSR) was achieved, regardless of the type of AF, in the course of the one-year follow-up, in 30 patients (94\%) in the Group GP and in 82 patients $(89 \%)$ in the Group LA $(p=0.485)$. Comparable results were also observed in both groups as regards the number of patients with NSR off anti-arrhythmic drugs (Group GP 16 (50\%), Group LA 28 (47\%), $p=0.184)$. Depending on the type of fibrillation at the end of follow-up, NSR was achieved in more than $90 \%$ of patients with paroxysmal and persistent fibrillation; the frequency of NSR was significantly lower in patients with long-standing persistent atrial fibrillation (97\% paroxysmal, 91\% persistent, $64 \%$ long-standing persistent, $p=0,003)$.

A total of 60 patients $(63 \%)$ were on anti-arrhythmic medication at discharge (Group GP 18 (53\%), Group LA $42(68 \%))$. In the sub-group of anti-arrhythmic medication, Amiodarone was the most frequently used drug (95\%), the combination of Amiodarone and ß-blockers was also frequently observed (62\%).

Stroke was observed in two patients in total $(2.17 \%$, $n=92$ ). One patient suffered a stroke with a phatic disorder without lateralization in the perioperative period, with subsequent normalization of the neurological deficit. Another case of stroke was observed in one patient in the course of the follow-up period.

During follow-up, electrical cardioversion was performed in eight patients in the Group GP (23\%), and 20 patients in the Group LA (31\%) ( $p=0.408)$. Eighty-five percent of cardioversions were performed during hospitalization after the surgery.

Permanent pacemaker was implanted in four patients from our file, already prior to the surgery. A total of eight patients $(8 \%, n=100)$ required an implantation of a permanent pacemaker in the postoperative period (3 patients in the Group GP $(8.6 \%, n=35)$, and 5 patients in the LA Group $(7.7 \%, n=65)(p=1.000))$. Serious heart rhythm disorders, resulting in implantation of a permanent pacemaker, included Sick Sinus Syndrome (SSS) in three cases, third-degree AV block (complete heart block) in two cases, junction rhythm, brady-form of AF, and asystole, always in one case each. In the subgroup of patients requiring pacemaker implantation in the postoperative period, a combined procedure at mitral and tricuspid valve was performed in six patients, revascularization of the myocardium (coronary bypass) in three patients, and aortal valve replacement in two patients. In one patient, implantation of epicardial electrode was performed in the course of the cardiac surgery procedure, due to findings of atrial fibrillation prior to the surgery. Planned implantation of Implantable Cardioverter Defibrillator (ICD) followed after the surgery. One patient required an implantation of permanent pacemaker due to brady-form of AF at 11 months following the surgical procedure. The resulting frequency of pacemaker implantation at the end of the follow-up period was $10 \%$.

During further assessment, we investigated the relation between the recurrence of $\mathrm{AF}$ and certain pre-operative variables. The group with the parameter of left atrium size $>50 \mathrm{~mm}$ included 22 patients with NSR (81\%), and five patients with $\operatorname{AF}(19 \%)(p=0.129)$; in the group of patients with mitral valvae disease, there were 60 patients with NSR (89\%), and 7 patients with AF (11\%) $(n=0.831)$; the group of patients with concomitant occurrence of mitral and tricuspid valvae defects contained 39 patients with $\operatorname{NSR}(87 \%)$, and 6 patients with AF $(13 \%)(p=0.458)$. No significant differences were found between the recurrence of $\mathrm{AF}$ and the above-listed variables.

In comparison of atrial fibrillation types was showed significantly higher AF recurrence in patients with longstanding persistent $\mathrm{AF}$ at the end 12-month follow up (paroxysmal $2.6 \%$, persistent $8.1 \%$, long-standing persistent $35.3 \%, p=0.003$ ). 


\section{Limitations}

In this report, we describe our early experiences with a mapping and ablation of GP in our low-volume center. The main limitations of our single-center study is retrospective analysis of data and relatively small number of patients, who underwent GP ablation. The left atrial cryoablation enhanced by mapping and ablation of GP (Group GP) was performed by only one surgeon, who was educated by proctor for Atricure. Although extreme caution was paid to proper mapping of GP, we cannot completely exclude the possibility of misdiagnosing the GP location. The posterior area of the left atrium isn't accesible for this procedure through median sternotomy approach. The consideration for safety of the patient always prevails over procedural completeness. LA ablation in patients of control group (Group LA) was performed by other surgeons of our team with one type of cryoprobe.

The surgery procedures were performed in the course of 30 months, with subsequent 12-month follow-up.

The limiting factor for performance of ablation due to AF was the size of the left atrium $\leq 60 \mathrm{~mm}$. Other factors, which also influenced the indication for ablation in some cases, included the duration of AF, extent of the surgical procedure, and haemodynamic condition of the patient prior to the surgery.

No statistically significant difference in pre-operative variables was observed between both compared groups, except for the incidence of Stroke/TIA in patient anamnesis. The assessment of heart rhythm was based on 24-h ECG monitoring.

\section{Discussion}

In our study, we refer on our early experience with GP ablation enhancing the left atrium cryoablation in the course of surgical treatment of AF in patients undergoing cardiac surgery.

As we have already mentioned in the introduction, autonomic nervous system plays an important role in the initiation and maintenance of AF. Key role is played namely with ganglionated plexi, which mediate and modulate interactions between the extrinsic and intrinsic autonomic nervous system [10, 17], and namely plexi localized in the atrial walls. These plexi are concentrated in centres with maximum incidence around orifices of pulmonary veins $[8,17,31-33]$.

Three key areas around the orifice of right-side PVs have been studied and presented in earlier publications: area between the right superior PV (RSPV) junction and LA, and superior vena cava (SVC) (dorsal right atrial subplexus) [9], medially from the right PV (RPVs) junction and LA, along interatrial groove (anterior right GP, ARGP) $[8,31]$ and between the inferior vena cava
(IVC) orifice and the left atrium, in a close proximity of the coronary sinus orifice (the inferior area, inferior right GP, IRGP) [8, 31]. ARGP and IRGP play an important role in the regulation of SA and AV nodi [9, 12, 17, 27, 34]. Other two GP centres are located around the orifice of left-side PVs. These left-side centres manifest a significantly lower activity than the right-side GP [35, 36]. Ligament of Marshall has been reported as another independent centre, which may be the source of focal activity [37].

Although we did not keep a strict protocol regarding the frequency of activity and GP ablations in individual areas during our study, we observed, in concordance with previous studies, a significantly higher GP activity on the right side, namely in the area of RSPV junction LA, behind SVC. Although the evidence regarding the influence of GP on the initiation and duration of AF is well known, the importance of GP ablation in the therapy of AF is not so clear, and studies, which have been performed so far, bring inconclusive evidence.

Experimental studies have proven influence of AF initiation in vagal denervation $[38,39]$, or chemical GP ablation [14]. In clinical practice, isolated GP ablation in the treatment of AF has been shown as insufficient [40, 41], and is not recommended [42]. Nevertheless, some authors support GP ablation as a part of a more complex catheterization $[21,22]$ or surgical ablation [24, 43-45]. In this relation, work of Pappone et al. [21] is frequently cited; the authors achieved 99\% success rate (freedom from AF) in the course of 12-month follow-up in patients with paroxysmal AF, in whom catheterization RF ablation was performed - circulation of PVs with a complete vagal denervation (= interruption of all vagal reflexes around PVs orifice).

In surgery, GP ablation is most frequently used as an enhancement of ablation therapy of AF alone performed from mini-invasive aproache, with or without the use of extracorporeal circulation, from bilateral thoracotomy $[45,46]$, or via fully thoracoscopic approach $[24,43,44]$. These studies present very good results achieved in the treatment of paroxysmal, persistent and long-standing persistent AF. However, most of these studies are retrospective, non-randomized clinical trials. There also exist works speaking against the use of GP ablation, presenting good results of AF treatment with ablation therapy only, without the use of GP ablation $[47,48]$. In these cases, certain role may have been played by the already mentioned GP topography. Most of the plexi are located in areas of ablation lines; that is why it is possible to presume that they will be destroyed (eliminated) already in the course of a standard ablation, without a targeted GP mapping. This theory is also supported by the findings of McClelland et al. [46]. The authors claim that following circumferential isolation of pulmonary veins with 
bipolar RF, the GP activity was limited by $79 \%$. Gelsomino et al. [49] use this theory to explain the failure to demonstrate the benefit of GP ablation in their study. This study was published last year, and similarly to our study, deals with the importance of GP ablation in patients with concomitant atrial fibrillation in the course of open-heart surgery. The authors compared groups of patients with persistent and long-standing persistent AF, in whom radiofrequency ablation was performed, including (Group 1), or not including (Group 2) GP ablation. The average follow-up period was 36.7 months. When comparing both groups, no difference was observed in the percentage of patients with NSR on-AAD (antiarrhythmic drugs) $(86.4 \%$ vs. $79.7 \%, p=0.07)$, or in the percentage of patients with NSR off-AAD at the end of the follow-up period $(75.5 \%$ vs. $67.8 \%, p=0.08)$. The performed risk analysis showed identical incidence of AF recurrence in both groups. Also the group of Alex et al. [50] was unsuccessful in their attempt to influence the incidence of AF in patients after CABG (coronary revascularization) procedure with heart denervation.

Other reasons standing in opposition of the performance of targeted GP ablation are the findings in the area of restoration of the heart autonomic system. The sympathetic re-innervation was described by Kaye et al. [51] already in 1993, in patients following heart transplantation. It is possible to object that in cases of heart transplantation, neuronal fibres are only interrupted, and direct destruction of neurons of the heart neural system is not performed. However, newer experimental studies bring clear evidence regarding re-innervation also following radiofrequency parasympathetic denervation (vagal denervation). Tests were also performed on canine hearts, the samples were monitored for the period of four weeks following ablation on average $[52,53]$. Similar results of neural function restitution have also been presented regarding experimental demonstration of administration of cryoenergy on the neural tissue. After administration of cryoenergy, the function of sensory and motor nerves is restored within several months [54-56]. This work cites only selected publications regarding GP ablation. Nevertheless, inconclusiveness of results and conclusions presented in these studies points towards the need of further research in the form of randomized, prospective clinical trials.

The issue of long-term efficacy of GP ablation has been discussed on numerous occasions and conclusion is not clear. On the basis of our early experiences and of recent experiences of other colleagues from cardiac centres we decided disrupt GP ablation performance and we are waiting for results of following studies. Although our team was educated by Atricure promotor, we performed GP ablation in only 35 patients and the learning curve may play role determinig our negative result.
A frequent topic of discussions regarding the surgical treatment of AF is the extent of the lesion set. This topic was analysed in the meta-analysis performed by Barnett et al. [57]; the results of this analysis show that surgical biatrial ablation (range, 92.0\%-87.1\%) in the analysed studies was more effective in the treatment of AF than the procedure limited to the left atrium (range, 86.1$73.4 \%$ ). Also the results of comparing various extent of ablation in the above cited work of the Italian authors [49] are in accordance with this finding; the authors concluded that biatrial ablation, as well as compete left atrial lesion set are suitable for improving rhythm outcomes, however, on more detailed analysis, a significantly lower incidence of AF recurrence was observed in patients with biatrial ablation when compared to the patients with left atrium ablation ( 18.5 vs. $36.5 \%, p=0.001)$, and absence of RA lesions (right atrium ablation) was determined as one of the predictors of AF recurrence.

In our present, as well as previous study [58], we managed to achieve similar good outcomes with performance of left atrium ablation in achievement and duration of NSR in the group of patients with paroxysmal and persistent AF. However, in the group of patients with long-standing persistent, or permanent AF, we observed a significantly higher AF recurrence, which increases with the period of follow-up.

These results and conclusions made us re-evaluate the extent of the ablation procedure performed at our centre, namely in patients with persistent and longstanding persistent $\mathrm{AF}$, and enhancing the procedure with ablation of RA lesions (Cox-MAZE IV procedure), the performance of which is aimed at the period of reperfusion, and thus should not have any influence on the cross-clamp time, the pump time, or the overall time of surgery [59]. Currently the Cox MAZE IV without GP ablation is preferred approach to treatment of concomitant $\mathrm{AF}$ in patients with persistent AF and mitral valve diseases at our centre.

Permanent pacemaker implantation is a known complication following heart surgery procedures. Its incidence reported in the literature reaches 1-11\% [60-65], and is comparable for heart surgeries with and without ablation. Elahi et al. [62] reported in their study of patients undergoing heart valve surgery the frequency of permanent cardiac stimulation of $6 \%$, and the identified predictors for implantation include reoperation, crossclamp time, combined procedure on heart valves and absence of NSR prior to the surgical procedure.

Low values were also reported by Merin et al. [63] (1.4\%), with a higher incidence in patients following aortic valve replacement (5.7\%), and the team of Gelsomino et al. [49] (0.6\% in the control group of patients undergoing cardiac surgery, with a various extent of ablation lesions set due to AF). On the other hand, there exist 
publications reporting the frequency of permanent cardiac stimulation around 20\% [66, 67]. In case of the study presented by Prasad et al. [66] the study subjects were patients after cardiac surgery with associated ablation due to AF, in most of whom sick sinus syndrome was diagnosed already prior to the surgery. In the group of patients with a normal function of the sinus node, the reported rate of implantation reached $8 \%$. In our patient group, a total of eight patients required permanent implantation $(8 \%)$ in the postoperative period (until discharge). At the end of the 12-month follow-up, the overall rate of implantation reached $10 \%$.

Left atrium appendage (LAA) elimination in patients with $\mathrm{AF}$ is performed due to the risk of thromboembolic complications. Dawson et al. [68] presented the results of studies dealing with this topic in his summary work. Although the benefit of LAA elimination was not confirmed, we perform this procedure in all patients with AF undergoing cardiac surgery. The procedure may be performed safely, without the need of prolongation of the overall time of surgery and increasing of the risk of perioperative bleeding [69]. As far as the surgical technique is concerned, use of instruments designed specifically for appendage occlusion, rather than use of staplers or the cut-and-sew technique is recommended [70]. Ligation or suture of the appendage is not recommended due to a high incidence of recanalization [71, 72]. Very good results have been published regarding the use of AtriClip device (Atricure, Inc., Westchester, OH, USA); use of this device leads not only to an ideal LAA occlusion and prevention of stroke but also to achieving electrical isolation of LAA and reduced AF recurrence [73].

At present, we use at our centre the technique cutand-sew for removal of LAA. The incidence of thromboembolic complications (stroke) among the patient population in our present study reaches approx. $2.2 \%$ at the end of one-year follow-up. In the previous study [58] performed at our centre, the incidence of thromboembolic events was $4.6 \%$, or $5.9 \%$, at the end of one-year and two-year follow-up, respectively. This corresponds with the frequency of thromboembolic events in patients after surgical ablation presented in published studies and results summarized in the meta-analysis by Gray et al. from 2011 [74].

The size of the left atrium is one of the factors influencing the AF recurrence. Gillinov et al. [61], in their study present a significantly higher AF recurrence in patients with the LA diameter of $60 \mathrm{~mm}(15 \%)$, in comparison with the LA size $>40 \mathrm{~mm}$. Damiano et al. [75] present up to $50 \%$ AF recurrence in LA diameter $>80 \mathrm{~mm}$ et LA reduction procedures presented in this study were not successful in the prevention of recurrence.

Upon analysis of our patient group, we did not observe any significant dependency of AF recurrence on the LA diameter in patients with LA $>50 \mathrm{~mm}$. This result may have been influenced by the relatively small number of study subjects and the fact that our patient file did not include any patients with LA $>60 \mathrm{~mm}$ undergoing surgery; however, one patient in the GP Group had LA diameter of $63 \mathrm{~mm}$.

\section{Conclusion}

We have not proven an improvement of results of left atrial cryoablation enhanced with a targeted RF ablation of GP in the AF treatment in patients undergoing cardiac surgery. Mapping and targeted GP ablation is not performed at our centre in other patients at the moment, as we are waiting for results of randomized controlled trials.

Cryoablation of the left atrium is a reasonable treatment of choice in patients with paroxysmal and persistent AF. In case of patients with long-standing persistent $\mathrm{AF}$, higher recurrence of AF has been observed.

\section{Abbreviations \\ AAD: Anti-arrhythmic drugs; AF: Atrial fibrillation; AIM: Acute myocardial infarction; ANS: Autonomic nervous system; ARGP: Anterior right ganglionated plexi; AV: Atrioventricular; CABG: Coronary artery bypass graft; ECC: Extracorporeal circulation; ECG: Electrocardiography; \\ ECHO: Echocardiography; GP: Gangionated plexi; ICD: Impantable cardioverter defibrillator; INR: Internal normalized ratio; IRGP: Inferior right ganglionated plexi; IVC: Inferior vena cava; LA: Left atrium; LAA: Left atrial appendage; MODS: Multiple organ dysfunction syndrome; NSR: Normal sinus rhythm; PVs: Pulmonary veins; RA: Right atrium; RF: Radiofrequency; RPVs: Right pulmonary veins; RSPV: Right superior pulmonary vein; \\ SA: Sinoatrial; SSS: Sick sinus syndrome; SVC: Superior vena cava; \\ TIA: Transitory ischemic attack}

\section{Acknowledgements}

We gratefully acknowledge Hana Tomášková, PhD. for performance of statistical analysis and Dr. Marek Bortliček for painting of Figs. 1, 2 and 3. The authors woudl like to thank Dr. Alaaddin Yilmaz for education, Mr. David Černý for his technical assistance and Mrs. Andrea Otisková for secretarial help.

\section{Availibility of data and materials}

The datasets generated and analysed during the current study are available from the corresponding author on reasonable request.

\section{Funding}

None.

\section{Authors' contributions}

All authors contributed equally. Both authors have read and approved the final manuscript, and agree to submit it for consideration for publication in your journal.

\section{Ethics approval and consent to participate}

The study was approved by the Ethics Committee of the University Hospital Ostrava (reference number 867/2016). Consent from the Ethics Committee was obtained retrospectively. Written informed consent was obtained from all patients prior surgery.

Consent for publication

Not applicable.

Competing interests

Both authors' declare that they have no competing interests. 


\section{Publisher's Note}

Springer Nature remains neutral with regard to jurisdictional claims in published maps and institutional affiliations.

Received: 19 November 2016 Accepted: 13 July 2017

Published online: 17 August 2017

\section{References}

1. Benjamin EJ, Levy D, Vaziri SM, D'Agostino RB, Belanger AJ, Wolf PA. Independent risk factors for atrial fibrillation in a population-based cohoret. The Framingham Heart Study. JAMA. 1994;271:840-4.

2. Wattigney WA, Mensah GA, Croft JB. Increasing trends in hospitalization for atrial fibrillation in the United States, 1985 through 1999: implications for primary prevention. Circulation. 2003;108:711-6.

3. Alessi $R$, Nusynowitz M, Abildskov JA, Moe GK. Nonuniform distribution of Vagal effects on the Atrial refractory period. Am J Physiol Leg Content. 1958;194:406.

4. Coumel P. Clinical approach to paroxysmal atrial fibrillation. Clin Cardiol. 1990:13:209-12.

5. Coumel P. Paroxysmal atrial fibrillation: a disorder of autonomic tone? Eur Heart J, 1994. 15(Suppl A):9-16.

6. Armour JA. Functional anatomy of intrathoracic neurons innervating the atria and ventricles. Heart Rhythm. 2010;7:994-6.

7. Chiou C-W, Eble JN, Zipes DP. Efferent Vagal Innervation of the canine atria and sinus and Atrioventricular nodes. Circulation. 1997;95:2573.

8. Armour JA, Murphy DA, Yuan BX, Macdonald S, Hopkins DA. Gross and microscopic anatomy of the human intrinsic cardiac nervous system. Anat Rec. 1997;247:289-98.

9. Pauza DH, Skripka V, Pauziene N, Stropus R. Morphology, distribution, and variability of the epicardiac neural ganglionated subplexuses in the human heart. Anat Rec. 2000;259:353-82.

10. Ardell JL. Structure and function of mammalian intrinsic cardiac neurons. In: Armour JA, Ardell JL, editors. Neurocardiology. Volume 1994. 2nd ed. New York: Oxford University Press; 1994. p. 95-114.

11. Quan KJ, Lee JH, Geha AS, Biblo LA, Van Hare GF, Mackall JA, Carlson MD. Characterization of sinoatrial parasympathetic innervation in humans. J Cardiovasc Electrophysiol. 1999;10:1060-5.

12. Ardell $\mathrm{J}$, Randall WC. Selective vagal innervation of sinoatrial and atrioventricular nodes in canine heart. Am J Phys. 1986;251(4 Pt 2):H764-73.

13. Coumel P, Attuel P, Lavallee J, Flammang D, Leclercq JF, Slama R. The atrial arrhythmia syndrome of vagal origin. Arch Mal Coeur Vaiss. 1978;71:645-56.

14. Scherlag BJ, Yamanashi W, Patel U, Lazzara R, Jackman WM. Autonomically induced conversion of pulmonary vein focal firing into atrial fibrillation. J Am Coll Cardiol. 2005:45:1878-86.

15. Sharifov OF, Fedorov W, Beloshapko GG, lushmanova AV, Rozenshtraukh LV: [Isoproterenol potentiates atrial fibrillation induced by acetylcholine]. Ross Fiziol Zhurnal Im IM Sechenova Ross Akad Nauk 2001, 87:1296-1308.

16. Po SS, Scherlag BJ, Yamanashi WS, Edwards J, Zhou J, Wu R, Geng N, Lazzara R, Jackman WM. Experimental model for paroxysmal atrial fibrillation arising at the pulmonary vein-atrial junctions. Heart Rhythm. 2006:3:201-8.

17. Hou Y, Scherlag BJ, Lin J, Zhang Y, Lu Z, Truong K, Patterson E, Lazzara R, Jackman WM, Po SS. Ganglionated plexi modulate extrinsic cardiac autonomic nerve input: effects on sinus rate, atrioventricular conduction, refractoriness, and inducibility of atrial fibrillation. J Am Coll Cardiol. 2007;50:61-8.

18. Haissaguerre M, Jais P, Shah DC, Takahashi A, Hocini M, Quiniou G, Garrigue S, Le Mouroux A, Le Metayer P, Clementy J. Spontaneous initiation of atrial fibrillation by ectopic beats originating in the pulmonary veins. $\mathrm{N}$ Engl $J$ Med. 1998;339:659-66.

19. Patterson E, Po SS, Scherlag BJ, Lazzara R. Triggered firing in pulmonary veins initiated by in vitro autonomic nerve stimulation. Heart Rhythm Off J Heart Rhythm Soc. 2005;2:624-31.

20. Ng J, Villuendas R, Cokic I, Schliamser JE, Gordon D, Koduri H, Benefield B, Simon J, Murthy SNP, Lomasney JW, Wasserstrom JA, Goldberger JJ, Aistrup $\mathrm{GL}$, Arora R. Autonomic remodeling in the left atrium and pulmonary veins in heart failure: creation of a dynamic substrate for atrial fibrillation. Circ Arrhythm Electrophysiol. 2011;4:388-96.

21. Pappone C, Santinelli V, Manguso F, Vicedomini G, Gugliotta F, Augello G, Mazzone P, Tortoriello V, Landoni G, Zangrillo A, Lang C, Tomita T, Mesas C, Mastella E, Alfieri O. Pulmonary vein denervation enhances long-term benefit after circumferential ablation for paroxysmal atrial fibrillation. Circulation. 2004;109:327-34
22. Katritsis DG, Giazitzoglou E, Zografos T, Pokushalov E, Po SS, Camm AJ. Rapid pulmonary vein isolation combined with autonomic ganglia modification: a randomized study. Heart Rhythm. 2011;8:672-8.

23. Nakagawa $H$, Scherlag $L, W u R$, et al. Addition of selective ablation of autonomic ganglia to pulmonary vein antrum isolation for treatment of paroxysmal and persistent atrial fibrillation. Circulation. 2004;110(III):543.

24. Yilmaz A, Geuzebroek GSC, Van Putte BP, Boersma LVA, Sonker U, De Bakker JMT, Van Boven W-J. Completely thoracoscopic pulmonary vein isolation with ganglionic plexus ablation and left atrial appendage amputation for treatment of atrial fibrillation. Eur J Cardiothorac Surg. 2010;38:356-60.

25. Edgerton JR, Brinkman WT, Weaver T, Prince SL, Culica D, Herbert MA, Mack MJ. Pulmonary vein isolation and autonomic denervation for the management of paroxysmal atrial fibrillation by a minimally invasive surgical approach. J Thorac Cardiovasc Surg. 2010;140:823-8.

26. Zheng S, Li Y, Han J, Zhang H, Zeng W, Xu C, Jia Y, Wang J, Guo K, Jiao Y, Meng $X$. Long-term results of a minimally invasive surgical pulmonary vein isolation and Ganglionic Plexi ablation for Atrial fibrillation. PLoS One. 2013;8:e79755.

27. Scherlag BJ, Nakagawa H, Jackman WM, Yamanashi WS, Patterson E, Po S, Lazzara R. Electrical stimulation to identify neural elements on the heart: their role in Atrial fibrillation. J Interv Card Electrophysiol. 2005;13:37-42.

28. Pokushalov E, Romanov A, Shugayev P, Artyomenko S, Shirokova N, Turov A, Katritsis DG. Selective ganglionated plexi ablation for paroxysmal atrial fibrillation. Heart Rhythm Off J Heart Rhythm Soc. 2009;6:1257-64.

29. Mack CA, Milla F, Ko W, Girardi LN, Lee LY, Tortolani AJ, Mascitelli J, Krieger $\mathrm{KH}$, Isom OW. Surgical treatment of Atrial fibrillation using argon-based Cryoablation during concomitant cardiac procedures. Circulation. 2005;112(9 suppl):11-6.

30. Doll N, Kiaii BB, Fabricius AM, Bucerius J, Kornherr P, Krakor R, Gummert JF, Walther T, Mohr FW. Intraoperative left atrial ablation (for atrial fibrillation) using a new argon cryocatheter: early clinical experience. Ann Thorac Surg. 2003;76:1711-5.

31. Nakagawa H, Scherlag BJ, Patterson E, Ikeda A, Lockwood D, Jackman WM. Pathophysiologic basis of autonomic ganglionated plexus ablation in patients with atrial fibrillation. Proc 2009 Dallas Symp State Art Atr Fibrillation AblationSymposium. 2009:6:S26-34

32. Shen MJ, Choi E-K, Tan AY, Lin S-F, Fishbein MC, Chen LS, Chen P-S. Neural mechanisms of atrial arrhythmias. Nat Rev Cardiol. 2012;9:30-9.

33. Scherlag B, Nakagawa H, Patterson E, Jackman W, Lazzara R, Po SS. The autonomic nervous system and atrial fibrillation: the roles of pulmonary vein isolation and ganglionated plexi ablation. J Atr Fibrillation. 2009;2(aug-sep):2.

34. Lachman N, Syed FF, Habib A, Kapa S, Bisco SE, Venkatachalam KL, Asirvatham SJ. Correlative anatomy for the electrophysiologist, part II: cardiac ganglia, phrenic nerve, coronary venous system. J Cardiovasc Electrophysiol. 2011;22:104-10.

35. Mehall JR, Kohut RM Jr, Schneeberger EW, Taketani T, Merrill WH, Wolf RK. Intraoperative Epicardial Electrophysiologic mapping and isolation of autonomic Ganglionic Plexi. Ann Thorac Surg. 2007;83:538-41.

36. Kondo $Y$, Ueda M, Watanabe M, Ishimura M, Kajiyama T, Hashiguchi N, Kanaeda T, Nakano M, Hiranuma Y, Ishizaka T, Matsumiya G, Kobayashi Y. Identification of left Atrial Ganglionated Plexi by dense Epicardial mapping as ablation targets for the treatment of concomitant Atrial fibrillation. Pacing Clin Electrophysiol. 2013:36:1336-41.

37. Hwang C, Wu T-J, Doshi RN, Peter CT, Chen P-S. Vein of Marshall Cannulation for the analysis of electrical activity in patients with focal Atrial fibrillation. Circulation. 2000;101:1503-5.

38. Chiou CW, Zipes DP. Selective vagal denervation of the atria eliminates heart rate variability and baroreflex sensitivity while preserving ventricular innervation. Circulation. 1998;98:360-8.

39. Elvan A, Pride HP, Eble JN, Zipes DP. Radiofrequency catheter ablation of the atria reduces inducibility and duration of atrial fibrillation in dogs. Circulation. 1995:91:2235-44

40. Katritsis D, Giazitzoglou E, Sougiannis D, Goumas N, Paxinos G, Camm AJ. Anatomic approach for Ganglionic Plexi ablation in patients with paroxysmal Atrial fibrillation. Am J Cardiol. 2008;102:330-4.

41. Zhou Q, Hou Y, Yang S. A meta-analysis of the comparative efficacy of ablation for atrial fibrillation with and without ablation of the ganglionated plexi. Pacing Clin Electrophysiol PACE. 2011;34:1687-94.

42. Calkins H, Kuck KH, Cappato R, Brugada J, Camm AJ, Chen S-A, Crijns HJG, Damiano RJ, Davies DW, DiMarco J, Edgerton J, Ellenbogen K, Ezekowitz MD, Haines DE, Haissaguerre M, Hindricks G, lesaka Y, Jackman W, Jalife J, 
Jais P, Kalman J, Keane D, Kim Y-H, Kirchhof P, Klein G, Kottkamp H, Kumagai K, Lindsay BD, Mansour M, Marchlinski FE, et al. 2012 HRS/EHRA/ ECAS expert consensus statement on catheter and surgical ablation of Atrial fibrillation: recommendations for patient selection, procedural techniques, patient management and follow-up, definitions, endpoints, and research trial design. Europace. 2012;14:528-606.

43. Edgerton JR, Edgerton ZJ, Weaver T, Reed K, Prince S, Herbert MA, Mack MJ. Minimally invasive pulmonary vein isolation and partial autonomic Denervation for surgical treatment of Atrial fibrillation. Ann Thorac Surg. 2008:86:35-9.

44. Sirak J, Jones D, Schwartzman D. The five-box thoracoscopic maze procedure. Ann Thorac Surg. 2010;90:986-9.

45. Wolf RK, Schneeberger EW, Osterday R, Miller D, Merrill W, Flege JBJ, Gillinov AM. Video-assisted bilateral pulmonary vein isolation and left atrial appendage exclusion for atrial fibrillation. J Thorac Cardiovasc Surg. 2005;130:797-802.

46. McClelland JH, Duke D, Reddy R. Preliminary results of a limited thoracotomy: new approach to treat atrial fibrillation. J Cardiovasc Electrophysiol. 2007;18:1289-95

47. Tekumit H, Uzun K, Riza Cenal A, Tataroglu C, Akinci E, Polat A. Midterm results of left atrial bipolar radiofrequency ablation combined with a mitral valve procedure in persistent atrial fibrillation. Cardiovasc J Afr. 2010;21:137-41.

48. Pison L, La Meir M, van Opstal J, Blaauw Y, Maessen J, Crijns HJ. Hybrid thoracoscopic surgical and transvenous catheter ablation of atrial fibrillation. J Am Coll Cardiol. 2012;60:54-61.

49. Gelsomino S, Lozekoot P, La Meir M, Lorusso R, Luca F, Rostagno C, Renzulli A, Parise O, Matteucci F, Gensini GF, Crjins HJGM, Maessen JG. Is ganglionated plexi ablation during maze IV procedure beneficial for postoperative long-term stable sinus rhythm? Int J Cardiol. 2015;192:40-8.

50. Alex J, Guvendik L. Evaluation of ventral cardiac Denervation as a prophylaxis against Atrial fibrillation after coronary artery bypass grafting Ann Thorac Surg. 2005;79:517-20

51. Kaye DM, Esler M, Kingwell B, McPherson G, Esmore D, Jennings G. Functiona and neurochemical evidence for partial cardiac sympathetic reinnervation after cardiac transplantation in humans. Circulation. 1993:88:1110-8.

52. Sakamoto S, Schuessler RB, Lee AM, Aziz A, Lall SC, Damiano RJ Jr. Vagal denervation and reinnervation after ablation of ganglionated plexi. J Thorac Cardiovasc Surg. 2010;139:444-52.

53. Oh S, Zhang Y, Bibevski S, Marrouche NF, Natale A, Mazgalev TN. Vagal denervation and atrial fibrillation inducibility: Epicardial fat pad ablation does not have long-term effects. Heart Rhythm. 2006;3:701-8.

54. Carter DC, Lee PW, Gill W, Johnston RJ. The effect of cryosurgery on peripheral nerve function. J R Coll Surg Edinb. 1972;17:25-31.

55. Beazley RM, Bagley DH, Ketcham AS. The effect of cryosurgery on peripheral nerves. J Surg Res. 1974;16:231-4.

56. Whittaker DK. Degeneration and regeneration of nerves following cryosurgery. Br J Exp Pathol. 1974;55:595-600.

57. Barnett SD, Ad N. Surgical ablation as treatment for the elimination of atrial fibrillation: a meta-analysis. J Thorac Cardiovasc Surg. 2006;131:1029-35.

58. Kolek M, Brat R. Cardiac rhythm and atrial transport function after surgical ablation of atrial fibrillation using cryoenergy: predictors and effectiveness of the procedure. Biomed Pap Med Fac Univ Palacky Olomouc Czechoslov. 2010;154:55-68.

59. Cox JL. A brief overview of surgery for atrial fibrillation. Ann Cardiothorac Surg. 2014;3:80-8.

60. McCarthy PM, Gillinov AM, Castle L, Chung M, Cosgrove D 3rd. The Coxmaze procedure: the Cleveland Clinic experience. Semin Thorac Cardiovasc Surg. 2000;12:25-9.

61. Gillinov AM, Sirak J, Blackstone EH, McCarthy PM, Rajeswaran J, Pettersson G, Sabik FJ 3rd, Svensson LG, Navia JL, Cosgrove DM, Marrouche N, Natale A. The Cox maze procedure in mitral valve disease: predictors of recurrent atrial fibrillation. J Thorac Cardiovasc Surg. 2005;130:1653-60.

62. Elahi MM, Lee D, V. Dhannapuneni RR: Predictors of permanent pacemaker implantation during the early postoperative period after valve surgery. Tex Heart Inst J 2006, 33:455-457.

63. Merin O, Ilan M, Oren A, Fink D, Deeb M, Bitran D, Silberman S. Permanent pacemaker implantation following cardiac surgery: indications and longterm follow-up. Pacing Clin Electrophysiol PACE. 2009;32:7-12.

64. Raanani E, Albage A, David TE, Yau TM, Armstrong S. The efficacy of the Cox/maze procedure combined with mitral valve surgery: a matched control study. Eur J Cardio-Thorac Surg Off J Eur Assoc Cardio-Thorac Surg. 2001;19:438-42.
65. Dawkins S, Hobson AR, Kalra PR, Tang ATM, Monro JL, Dawkins KD. Permanent pacemaker implantation after isolated aortic valve replacement: incidence, indications, and predictors. Ann Thorac Surg. 2008;85:108-12.

66. Prasad SM, Maniar HS, Camillo CJ, Schuessler RB, Boineau JP, Sundt TM III, Cox JL, Damiano RJ Jr. The Cox maze III procedure for atrial fibrillation: long-term efficacy in patients undergoing lone versus concomitant procedures. J Thorac Cardiovasc Surg. 2003;126:1822-7.

67. Damiano RJ Jr, Gaynor SL, Bailey M, Prasad S, Cox JL, Boineau JP, Schuessler RP. The long-term outcome of patients with coronary disease and atrial fibrillation undergoing the cox maze procedure. J Thorac Cardiovasc Surg. 126:2016-21.

68. Dawson AG, Asopa S, Dunning J. Should patients undergoing cardiac surgery with atrial fibrillation have left atrial appendage exclusion? Interact Cardiovasc Thorac Surg. 2010;10:306-11.

69. Healey JS, Crystal E, Lamy A, Teoh K, Semelhago L, Hohnloser SH, Cybulsky I, Abouzahr L, Sawchuck C, Carroll S, Morillo C, Kleine P, Chu V, Lonn E, Connolly SJ. Left Atrial appendage occlusion study (LAAOS): results of a randomized controlled pilot study of left atrial appendage occlusion during coronary bypass surgery in patients at risk for stroke. Am Heart J. 2005;150:288-93.

70. Dunning J, Nagendran M, Alfieri OR, Elia S, Kappetein AP, Lockowandt U, Sarris GE, Kolh PH. On behalf of the EACTS clinical guidelines committee: guideline for the surgical treatment of atrial fibrillation. Eur J Cardiothorac Surg. 2013;

71. Kanderian AS, Gillinov AM, Pettersson GB, Blackstone E, Klein AL. Success of surgical left atrial appendage closure: assessment by transesophageal echocardiography. J Am Coll Cardiol. 2008;52:924-9.

72. Katz ES, Tsiamtsiouris T, Applebaum RM, Schwartzbard A, Tunick PA, Kronzon I. Surgical left atrial appendage ligation is frequently incomplete: a transesophageal echocardiograhic study. J Am Coll Cardiol. 2000;36:468-71.

73. Starck CT, Steffel J, Emmert MY, Plass A, Mahapatra S, Falk V, Salzberg SP. Epicardial left atrial appendage clip occlusion also provides the electrical isolation of the left atrial appendage. Interact Cardiovasc Thorac Surg. 2012;15:416-8.

74. Michael Gray R, Nagendran M, Maruthappu M. Is it safe to stop anticoagulants after successful surgery for atrial fibrillation? Interact Cardiovasc Thorac Surg. 2012;13:642-9.

75. Damiano RJJ, Schwartz FH, Bailey MS, Maniar HS, Munfakh NA, Moon MR, Schuessler RB. The Cox maze IV procedure: predictors of late recurrence. J Thorac Cardiovasc Surg. 2011;141:113-21.

\section{Submit your next manuscript to BioMed Central and we will help you at every step:}

- We accept pre-submission inquiries

- Our selector tool helps you to find the most relevant journal

- We provide round the clock customer support

- Convenient online submission

- Thorough peer review

- Inclusion in PubMed and all major indexing services

- Maximum visibility for your research

Submit your manuscript at www.biomedcentral.com/submit
) Biomed Central 